\title{
An axillary granular cell tumor: A rare neoplasm at an unusual site
}

\author{
Issam Msakni, Aya Khemir, Faten Gargouri, Nada Mansouri, Karima Tlili, Besma Laabidi
}

Pathology Department, Military Hospital of Tunis, Monfleury, Tunis, Tunisia; Faculty of Medicine of Tunis, University of Tunis el Manar, Tunis, Tunisia

Corresponding author: Dr. Issam Msakni, E-mail: msaknissam@yahoo.fr

\begin{abstract}
A granular cell tumor (GCT) is a rare neoplasm occurring usually in submucosal and subcutaneous tissues anywhere in the body, affecting mainly the head and neck. GCTs at unusual anatomic sites, such as the breast or the axillary extension, could be taken for invasive carcinoma. We report the case of a 30-year-old male who presented himself with an axillary nodule. A physical examination revealed a firm and painless subcutaneous tumor on ulcerated skin. Lymphoma and lymph node metastasis were suspected. An imaging survey was negative outside the axillary nodule. The tumor was surgically removed. A microscopic examination showed the typical features of a benign GCT. Surgical margins were negative. No recurrence has been observed within a 6-month follow-up period. A GCT can mimic a malignancy since it presents itself as an axillary nodule, and requires complete surgical resection with clear margins.
\end{abstract}

Key words: Granular cell tumor; Abrikossoff; Axillary; Malignancy

\section{INTRODUCTION}

Granular cell tumors (GCTs) are rare [1-6], first described by Abrikossoff in 1926 [7]. Immunohistochemical and ultrastructural studies have demonstrated their Schwannian differentiation [8]. A slight female to male and black to white predominance exists $[1,3,6,9,10]$. GCTs occur in adults between the fourth and sixth decade of life $[3,7,10,11]$. They develop mainly in the head and neck. As for the oral cavity, the tongue is most affected in up to $65 \%$ of cases $[1,3,6,9,10,12,13]$. Cases of GCTs of the digestive tract, back, and vulva have been reported as well $[1,3,4,11,14-16]$. The pathogenesis of the GCT has not yet been elucidated $[1,6,12]$. GCTs may also develop at unusual anatomic sites and can, therefore, be taken for other tumors, essentially malignant. The breast and axillary extension are unusual sites also affected by GCTs in almost $5-8 \%$ of cases $[5,6,13,17,18]$. Such a tumor can clinically and/or radiographically mimic an invasive carcinoma.

Herein, we report a new case of an axillary GCT in a young male patient.

\section{CASE REPORT}

A 30-year-old male patient without a particular medical history presented himself to the department of dermatology with an axillary nodule. A physical examination revealed a firm painless axillary subcutaneous tumor on ulcerated skin, initially presumed to be a lymphoma or a metastatic lymph node. An imaging survey and laboratory tests were within normal limits. The nodule was surgically removed. Upon gross examination, it was a mass $1 \mathrm{~cm}$ in diameter. A microscopic examination revealed a wellcircumscribed proliferation occupying the dermis. The overlying epidermis showed pseudoepitheliomatous hyperplasia and was focally ulcerated. Large and polygonal tumor cells had abundant eosinophilic and granular cytoplasm with small nuclei in a central position (Fig. 1). There was no nuclear pleomorphism or tumor necrosis. The tumor cells stained positively for S100 (Fig. 2). Surgical margins were clear. No recurrence has been observed within a 6-month follow-up period.

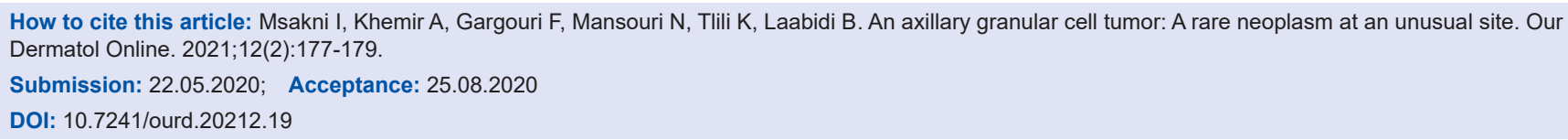




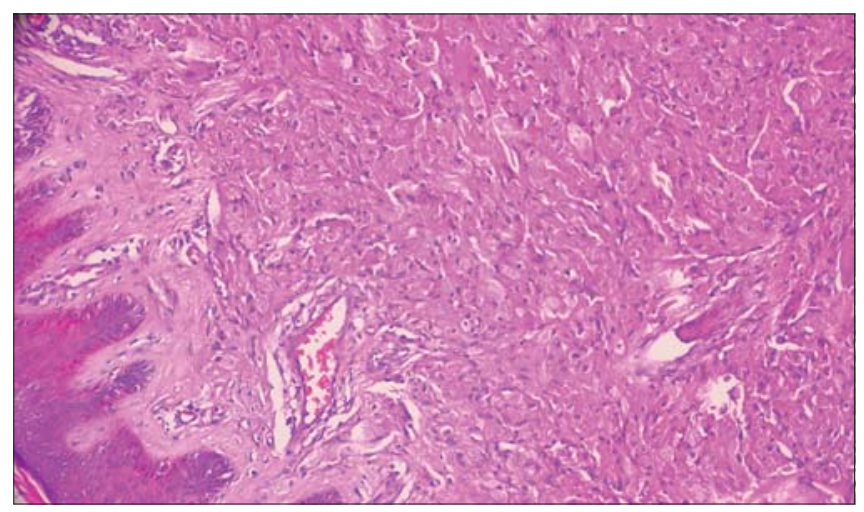

Figure 1: A benign tumor occupying the dermis, made of medium-sized cells with abundant and granular cytoplasm and regular nuclei (insert $x$ 400) (H\&E, 100x).

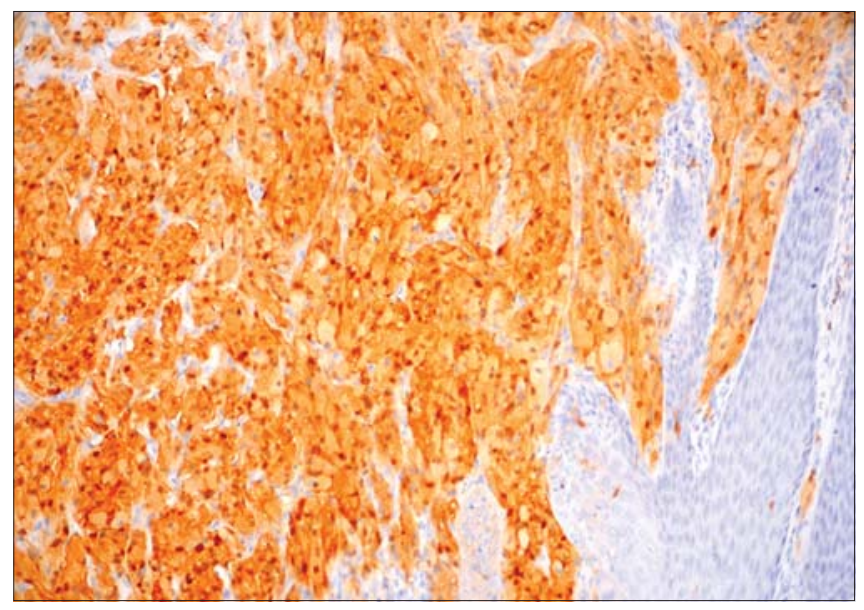

Figure 2: The diffuse positivity of tumor cells for $\mathrm{S} 100$ immunostaining (H\&E, 100x).

\section{DISCUSSION}

GCTs are rare nonmelanocytic tumors with Schwannian differentiation [1-6], usually reported as benign slowgrowing tumors $[1,3,5,12]$. They affect the breast and axillary extension in almost $5-8 \%$ of cases. Clinically, GCTs present themselves as asymptomatic isolated nodules less than $4 \mathrm{~cm}$ in diameter, as in our case. However, around $5 \%$ of patients may show multiple nodules $[1,4,9]$. Most of them are sporadic $[3,6]$. Other symptoms, such as pruritus and pain, have been reported $[11,16]$. Malignancy is suspected in cases at unusual anatomic sites, rapidly growing masses more than $5 \mathrm{~cm}$ in diameter, and skin ulcerations $[1,5,6,10,12]$. In our case, the clinical presentation was challenging because the isolated axillary nodule with ulcerated skin mimicked a malignancy. Such diagnostic pitfalls have been reported in many cases of GCTs of the breast and axillary extension. The GCT mimicked an invasive carcinoma clinically and radiographically $[2,5,6]$.
Histologic diagnosis of GCTs is usually unchallenging. These tumors present themselves as well-circumscribed or infiltrative proliferations polygonal in shape with abundant and granular cytoplasm. Their nuclei are small and have a central position. GCTs are usually separated by thin bands of connective tissue $[1,4-6,9,10,12]$, and, although they are usually reported as benign, malignant forms exist, even if rare, accounting for less than 3\% of all cases of GCTs reported in the literature $[7,9,10,12]$. Most cases of GCTs in the breast and axillary region were histologically diagnosed as malignant GCTs $[8,18,19]$. The unique criteria confirming malignancy is the presence of metastasis [7]. However, some classification systems have been established to predict the malignant potential of GCTs. Fanburg-Smith et al. were the first to establish a classification system of six items defining three categories of GCTs: benign, malignant, and atypical $[7,10,12]$. In order to refine this classification, Nasser et al. reviewed 48 cases of GCTs, concluding that necrosis and mitotic activity were most correlated with malignancies. They also showed that Ki67 may be helpful in cases difficult to classify [7]. Conventional GCT cells stain positively for S100, CD68, and neuronspecific enolase $[1,6,10,11]$. Immunohistochemistry is of great help to rule out differentials and mimickers of GCTs, such as atypical fibroxanthoma, rhabdomyoma, dermatofibroma, and hibernoma [7]. Benign GCTs require surgical removal with negative margins to prevent recurrence $[1,2,5,7]$. Malignant forms with metastases complicate survival and increase mortality rates, which may reach $40 \%[4,7,12]$. The benefits of adjuvant therapies after surgical excision have not been proven so far [12].

To conclude, the clinical presentation observed in our case eventually confirmed the diagnosis of malignancy. The negative results of the imaging survey and laboratory tests prompted surgical removal of the tumor mass. A diagnosis of a benign GCT with negative margins was reached and spared our patient from overtreatment.

\section{Consent}

The examination of the patient was conducted according to the principles of the Declaration of Helsinki.

The authors certify that they have obtained all appropriate patient consent forms, in which the patients gave their consent for images and other clinical information to be included in the journal. The patients understand that their names and initials will not be published and due effort will be made to conceal their identity, but that anonymity cannot be guaranteed. 


\section{REFERENCES}

1. Mehta V, Balachandran C, Rao L, Geeta V. Giant granular cell tumor of the vulva. Indian J Dermatol Venereol Leprol. 2010;76:263-5.

2. Fujiwara K, Maeda I, Mimura H. Granular cell tumor of the breast mimicking malignancy: a case report with a literature review. Acta Radiol Open. 2018;7:205846011881653.

3. Barros Pereira I, Khan A. Vulvar granular cell tumor: a rare tumor in an unusual location. J Clin Gynecol Obstet. 2015;4:279-81.

4. Cheewakriangkrai C, Sharma S, Deeb G, Lele S. A rare female genital tract tumor: Benign granular cell tumor of vulva: case report and review of the literature. Gynecol Oncol. 2005;97:656-8.

5. Pergel A, Yucel AF, Karaca AS, Aydin I, Sahin DA, Demirbag N. A therapeutic and diagnostic dilemma: granular cell tumor of the breast. Case Rep Med. 2011;2011:1-3.

6. Bui M, Mahar M, Reis-Filho JS. Peripheral nerve sheath tumors. In: WHO classification of tumors: Breast tumors. $5^{\text {th }}$ ed. Lyon: Dilani Lokuhetty, Waleria A. white, Reiko Watanabe, Ian A. Cree; 2019. p. 215-6.

7. Nasser H, Ahmed Y, Szpunar SM, Kowalski PJ. Malignant granular cell tumor: A look into the diagnostic criteria. Pathol Res Pract. 2011;207:164-8.

8. Akahane K, Kato K, Ogiso S, Sakaguchi K, Hashimoto M, Ishikawa A, et al. Malignant granular cell tumor of the breast: case report and literature review. Breast Cancer. 2015;22:317-23.

9. Alnashwan YA, Ali KAH, Amr SS. Metastasizing malignant granular cell tumor (Abrikossoff tumor) of the anterior abdominal wall, with prolonged survival. Case Rep Pathol. 2019;2019:1-8.

10. Aoyama K, Kamio T, Hirano A, Seshimo A, Kameoka S. Granular cell tumors: a report of six cases. World J Surg Oncol. 2012;10:204.

11. Lazar A. Granular cell Tumor. In: WHO classification of tumors of soft tissue and bone. $4^{\text {th }}$ ed. Lyon: Christopher D.M fletcher, Julia A.bridge, Pancras C.W Hogendoorn, Fedrik Mertens; 2013. p. 178-9.

12. Singh V, Gunasagaran J, Pailoor J. Granular cell tumour: malignant or benign? Singapore Med J. 2015;56:513-7.

13. Pohlodek K, Jáni P, Mečiarová I. Granular cell tumor in axillary region: a rare entity. Mol Clin Oncol. 2018;8:579-81.

14. An S, JangJ, Min K, Kim MS, Park H, Park YS, etal. Granular cell tumor of the gastrointestinal tract: histologic and immunohistochemical analysis of 98 cases. Hum Pathol. 2015;46:813-9.

15. McGuire LS, Yakoub D, Möller MG, Rosenberg A, Livingstone A. Malignant granular cell tumor of the back: a case report and review of the literature. Case Rep Med. 2014;2014:1-5.

16. de Misa RF, Castro V, Suárez J, Perera A. Pruritic vulvar nodule in a black woman. Arch Dermatol. 2000;136:1165-70.

17. Costa Almeida CE, Caroço T, Silva M, Albano MN. Abrikossoff's tumour on the upper limb: a rare presentation. BMJ Case Rep. 2017;bcr-2017-222006.

18. Chen J, Mehraj V, Szabo J, Routy B, Michel RP, Routy JP. Multiple remissions of extracavitary primary effusion lymphoma treated with a single cycle of liposomal doxorubicin in a patient infected with HIV. Curr Oncol. 2018;25:e592-6.

19. Tatar BE, Gelbal C, Sezgiç M, Karakol P, Uslu C, Kabul S. A rare case: malignant granular cell tumor in axillary region. BMB. 2019;4:106-9.

Copyright by Issam Msakni, et al. This is an open access article distributed under the terms of the Creative Commons Attribution License, which permits unrestricted use, distribution, and reproduction in any medium, provided the original author and source are credited.

Source of Support: Nil, Conflict of Interest: None declared. 